\title{
miR-185 inhibits non-small cell lung cancer cell proliferation and invasion through targeting of SOX9 and regulation of Wnt signaling
}

\author{
ZHENGWEN LEI ${ }^{1-3}$, HONGCAN SHI ${ }^{2,3}$, WEI LI' ${ }^{2}$, DUONAN YU², \\ FEIYANG SHEN ${ }^{2}$, XI YU ${ }^{2}, \mathrm{DAN} \mathrm{LU}^{4}, \mathrm{CHAO} \mathrm{SUN}^{3}$ and KAI LIAO ${ }^{2}$ \\ ${ }^{1}$ Department of Cardiac-Vascular Surgery, The Second Xiangya Hospital, Central South University, \\ Changsha, Hunan 410011; ${ }^{2}$ Center of Translational Medicine, Medical School of Yangzhou University; \\ ${ }^{3}$ Department of Cardiac-Thoracic Surgery, Northern Jiangsu People's Hospital; ${ }^{4}$ Department of \\ Obstetrical, Northern Jiangsu People's Hospital, Yangzhou, Jiangsu 225000, P.R. China
}

Received April 4, 2017; Accepted October 10, 2017

DOI: $10.3892 / \mathrm{mmr} .2017 .8050$

\begin{abstract}
SRY-box 9 (SOX9) is an important transcription factor required for development, which has additionally been reported to be an independent prognostic indicator for the survival of patients with non-small cell lung cancer (NSCLC). Accumulating evidence has indicated that dysregulation of microRNAs (miRNAs/miRs) may contribute to the initiation and progression of cancer. SOX 9 may be regulated by a number of miRNAs in different types of cancer, including in NSCLC. The present study sought to identify novel candidate miRNAs associated with SOX9 in NSCLC using online tools, and investigated the detailed functions of miR-185, which suppressed SOX9 mRNA expression most strongly out of the candidate miRNAs. It was observed that ectopic miR-185 expression significantly suppressed NSCLC cell proliferation, invasion and migration. Using luciferase reporter gene and RNA immunoprecipitation assays, SOX9 was confirmed to be a direct target of miR-185. In addition, the downstream Wnt signaling-associated factors $\beta$-catenin and c-Myc proto-oncogene protein $(\mathrm{Myc})$ were demonstrated to be inhibited by miR-185 overexpression. SOX9, $\beta$-catenin and c-Myc mRNA expression was significantly upregulated in NSCLC tissues, and was inversely correlated with miR-185 expression. The results of the present study demonstrated that rescuing miR-185 expression in NSCLC, thereby inhibiting SOX9 expression and the downstream Wnt signaling, and leading to the suppression of NSCLC cell proliferation, invasion and migration, may be a promising strategy for the treatment of NSCLC.
\end{abstract}

Correspondence to: Professor Hongcan Shi, Center of Translational Medicine, Medical School of Yangzhou University, 11 Huaihai Road, Yangzhou, Jiangsu 225000, P.R. China

E-mail: 317888567@qq.com

Key words: microRNA-185, SRY-box 9, non-small cell lung cancer, Wnt signaling, proliferation

\section{Introduction}

Lung cancer is among the most lethal types of cancer in men and women (1). Over one-half of patients diagnosed with non-small cell lung cancer (NSCLC) succumb to the disease within one year of diagnosis, and the 5-year survival rate is $\sim 17.8 \%$ (2). Lung cancer consists of two principal types: Small-cell lung carcinoma, and non-small-cell lung carcinoma (NSCLC), accounting for $\sim 15$ and $85 \%$ of all cases of lung cancer, respectively $(3,4)$. Despite advances in treatment, the prognosis is generally poor. Following complete surgical resection of stage IA disease, the 5-year survival rate of patients is $67 \%$, although the 5-year survival rate of individuals with stage IV NSCLC is $<1 \%$ (5). One reason for such a low survival rate is that patients do not receive treatment early enough in the disease progression for it to be effective, which is associated with the highly metastatic character of NSCLC. The molecular mechanism underlying the progression of NSCLC requires further research, with a view to developing therapies based on molecular signatures within tumors. There is marked clinical value in early detection and the provision of effective interventions to treat NSCLC.

SRY-box 9 (SOX9) is an important transcription factor required for development, which regulates the expression of target genes in associated pathways (6). SOX9 was first identified to be an important regulator of cartilage and male gonad development, with mutations in SOX9 causing autosomal sex reversal $(7,8)$. Previously, SOX9 has been observed to be upregulated in a number of tumor types, including lung adenocarcinoma, breast carcinoma, colorectal cancer and prostate cancer (6-9), in addition to NSCLC (9). Additionally, multivariate analysis illustrated that $\mathrm{SOX} 9$ upregulation may be an independent prognostic indicator for the survival of patients with NSCLC (9).

microRNAs (miRNAs/miRs) are class of endogenous, small non-coding RNA molecules with a length of 18-25 nucleotides, that negatively regulate mRNA stability and/or repress $m R N A$ translation by binding to the $3^{\prime}$ untranslated region (UTR) $(10,11)$. Increasing evidence has suggested that 
miRNAs serve important roles in diverse biological processes, including cell proliferation, the cell cycle, differentiation, apoptosis and metastasis (12-14). Deregulation of miRNAs has been widely reported to be involved in the development of various types of cancer, including NSCLC (15-17), which may provide a novel and promising way to treat NSCLC. A number of miRNAs have been reported to regulate NSCLC cell proliferation, invasion and migration via regulation of SOX9. miR-592 and miR-124 function as tumor suppressors in NSCLC by suppressing the activity of $\operatorname{SOX} 9(18,19)$.

In the present study, a series of online tools was used to screen for novel candidate miRNAs of SOX9. In addition, functional and mechanistic assays were employed to evaluate the detailed roles of the candidate miRNAs in the regulation of NSCLC cell proliferation, invasion and migration, in addition to the regulation of SOX9. The results of the present study provided a novel theoretical and experimental basis for biomarkers and individualized therapy for NSCLC.

\section{Materials and methods}

Tissue samples, cell lines and cell transfection. A total of 42 paired NSCLC tissues and the matched adjacent normal tissues were collected. All samples were obtained from patients who underwent surgical resection at Northern Jiangsu People's Hospital (Yangzhou, China) between January 2013 and January 2014. The tissues were snap-frozen in liquid nitrogen, and subsequently stored at $-80^{\circ} \mathrm{C}$. The present study was approved by the Ethic Committee of Northern Jiangsu People's Hospital and all participants provided written informed consent.

The immortalized human bronchial epithelial cell BEAS-2B, human NSCLC cell lines A549, H1299, H1650, and the SK-MES-1 NSCLC cell line were purchased from the American Type Culture Collection (Manassas, VA, USA). Cells were cultured in RPMI-1640 medium (Invitrogen; Thermo Fisher Scientific, Inc., Waltham, MA, USA) supplemented with $10 \%$ fetal bovine serum (Gibco; Thermo Fisher Scientific, Inc.) at $37^{\circ} \mathrm{C}$ in a humidified atmosphere with $5 \%$ $\mathrm{CO}_{2}$.

The expression of miR-105, miR-138, miR-15a, miR-15b, miR-19a, miR-19b, miR-206, miR-30b, miR-424, miR-497 and miR-185 was achieved by transfection of miR-105, miR-138, miR-15a, miR-15b, miR-19a, miR-19b, miR-206, miR-30b, miR-424, miR-497 and miR-185 mimics or miR-185 inhibitor (Shanghai Genepharma Co., Ltd., Shanghai, China) using Lipofectamine 2000 (Invitrogen; Thermo Fisher Scientific, Inc.). Cells were plated in 6-well plates or 96-well plates $\left(6 \times 10^{3}\right.$ cells/well), transfected with $50 \mathrm{nM}$ miRs mimics or inhibitors, incubated for 24 or $48 \mathrm{~h}$ and used for further assays or RNA/protein extraction. The following miR sequences were used in the present study: Hsa-miR-105-5p (accession no. MIMAT0000102) 5'-UCAAAUGCUCAGACU CCUGUGGU-3', mimic F: 5'-UCAAAUGCUCAGACUCCU GUGGU-3', R: 5'-CACAGGAGUCUGAGCAUUUGAUU-3', inhibitor 5'-ACCACAGGAGUCUGA GCAUUUGA-3'; hsa-miR-138-5p(accession no.MIMAT0000430)5'-AGCUGG UGUUGUGAAUCAGGCCG-3', mimic F: 5'-AGCUGGUGU UGUGAAUCAGGCCG-3', R: 5'-GCCUGAUUCACAACA CCAGCUUU-3', inhibitor 5'-CGGCCUGAUUCACAACAC
CAGCU-3'; hsa-miR-15a-5p (accession no. MIMAT0000068) 5'-UAGCAGCACAUAAUGGUUUGUG-3', mimics F: 5'-UAGCAGCACAUAAUGGUUUGUG-3', R: 5'-CAA ACCAUUAUGUGCUGCUAUU-3', inhibitor. 5'-CACAAA CCAUUAUGUGCUGCUA-3'; hsa-miR-15b-5p (accession no. MIMAT0000417). 5'-UAGCAGCACAUCAUGGUU UACA-3', mimic F: 5'-UAGCAGCACAUCAUGGUUUAC A-3', 5'-UAAACCAUGAUGUGCUGCUAUU-3', inhibitor 5'-UGUAAACCAUGAUGUGCUGCUA-3'; hsa-miR-19a-3p (accession no. MIMAT0000073) 5'-UGUGCAAAUCUA UGCAAAACUGA-3', Mimic F: 5'-UGUGCAAAUCUA UGCAAAACUGA-3', R: 5'-AGUUUUGCAUAGAUUUGC ACAUU-3', inhibitor 5'-UCAGUUUUGCAUAGAUUUGCA CA-3'; hsa-miR-19b-3p (accession no. MIMAT0000074) 5'-UGUGCAAAUCCAUGCAAAACUGA-3', mimic F: 5'-UGUGCAAAUCCAUGCAAAACUGA-3', R: 5'-AGU UUUGCAUGGAUUUGCACAUU-3', inhibitor 5'-UCA GUUUUGCAUGGAUUUGCACA-3'; hsa-miR-206 5p (accession no. MIMAT0000462) 5'-UGGAAUGUAAGG AAGUGUGUGG-3', mimic F: 5'-UGGAAUGUAAGGAAG UGUGUGG-3', R: 5'-ACACACUUCCUUACAUUCCAU U-3'; inhibitor 5'-CCACACACUUCCUUACAUUCCA-3'; hsa-miR-30b-5p (accession no. MIMAT000042) 5'-UGUAAA CAUCCUACACUCAGCU-3', mimics F: 5'-UGUAAACAU CCUACACUCAGCU-3', R: 5'-CUGAGUGUAGGAUGU UUACAUU-3', inhibitor 5'-AGCUGAGUGUAGGAUGUU UACA-3'; hsa-miR-424-5p (accession no. MIMAT0001341) 5'-CAGCAGCAAUUCAUGUUUUGAA-3', mimics. F: 5'-CAGCAGCAAUUCAUGUUUUGAA-3', R: 5'-CAAAAC AUGAAUUGCUGCUGUU-3', inhibitor 5'-UUCAAAACA UGAAUUGCUGCUG-3'; hsa-miR-497-5p (accession no. MIMAT0002820) 5'-CAGCAGCACACUGUGGUUUGU-3', mimics F: 5'-CAGCAGCACACUGUGGUUUGU-3', R: 5'-AAACCACAGUGUGCUGCUGUU-3', inhibitor 5'-ACA AACCACAGUGUGCUGCUG-3'; hsa-miR-185-5p (accession no. MIMAT0000455) 5'-UGGAGAGAAAGGCAGUUC CUGA-3', mimics F: 5'-UGGAGAGAAAGGCAGUUCCUG A-3', R: 5'-AGGAACUGCCUUUCUCUCCAUU-3', inhibitor, 5'-UCAGGAACUGCCUUUCUCUCCA-3'; inhibitor NC 5'-CAGUACUUUUGUGUAGUACAA-3'; mimics NC, sense 5'-UUCUCCGAACGUGUCACGUTT-3', antisense 5'-ACG UGACACGUUCGGAGAATT-3'.

miRNA prediction. Online tools including miRWalk (zmf.umm.uni-heidelberg.de/apps/zmf/mirwalk), miRanda (http://www.microrna.org/microrna/home.do), RNA22 (20), starBase (http://starbase.sysu.edu.cn/) and Targetscan (www.targetscan.org) were used to predict the candidate miRNAs which are associated with SOX9.

RNA extraction and SYBR green quantitative polymerase chain reaction $(q P C R)$ analysis. The total RNA was extracted from cells using TRIzol reagent (Invitrogen; Thermo Fisher Scientific, Inc.) and mature miR-185 expression was detected in cells using a Hairpin-it ${ }^{\mathrm{TM}}$ miRNAs qPCR kit (Shanghai Genepharma Co., Ltd.). Thermocycling conditions included an initial step at $98^{\circ} \mathrm{C}$ for $1 \mathrm{~min}$, and 40 cycles at $95^{\circ} \mathrm{C}$ for $5 \mathrm{sec}$ and at $62-68^{\circ} \mathrm{C}$ for $15 \mathrm{sec}$, $72^{\circ} \mathrm{C}$ for $2 \mathrm{~min}$ and final extension at $72^{\circ} \mathrm{C}$ for $10 \mathrm{~min}$. The expression of small nucleolar RNU6B was used as an 
endogenous control. SOX9, $\beta$-catenin and c-Myc expression was measured using a SYBR green qPCR assay (One Step SYBR PrimerScript RT-PCR Kit, Takara Biotechnology Co., Ltd., Dalian, China). Reverse transcription and amplification were performed at $42^{\circ} \mathrm{C}$ for $15 \mathrm{~min}$, followed by 40 cycles of $95^{\circ} \mathrm{C}$ for $5 \mathrm{sec}$ and $60^{\circ} \mathrm{C}$ for $34 \mathrm{sec}$ using an ABI Prism 7900 HT (Applied Biosystems; Thermo Fisher Scientific, Inc.). The following primer sequences were used for the PCR: RNU6B, reverse 5'-AACGCTTCACGAATTTGCGT-3', forward 5'-CTCGCTTCGGCAGCACA-3'; SOX9, forward 5'-AGCGAACGCACATCAAGAC-3', reverse 5'-CTGTAG GCGATCTGTTGGGG-3'; $\beta$-catenin, forward 5'-AAAGCG GCTGTTAGTCACTGG-3', reverse 5'-CGAGTCATTGCA TACTGTCCAT-3'; c-Myc, forward 5'-GGCTCCTGGCAA AAGGTCA-3', reverse 5'-CTGCGTAGTTGTGCTGAT GT-3'; GAPDH, forward 5'-GGAGCGAGATCCCTCCAA AAT-3', reverse 5'-GGCTGTTGTCATACTTCTCATGG-3'. Data were analysed using the $2^{-\Delta \Delta C q}$ method (21).

MTT assay. A modified MTT assay was used to evaluate cell viability. A total of $24 \mathrm{~h}$ following seeing into 96 -well plates (5,000 cells/well), cells were transfected with miR-185 mimics or miR-185 inhibitor. A total of $48 \mathrm{~h}$ following transfection, $20 \mu 1$ MTT (at a concentration of $5 \mathrm{mg} / \mathrm{ml}$; Sigma-Aldrich; Merck KGaA, Darmstadt, Germany) was added, and the cells were incubated for an additional $4 \mathrm{~h}$ in a humidified incubator. A total of $200 \mu \mathrm{l}$ dimethyl sulfoxide was added following discarding of the supernatant to dissolve the formazan. Optical density $(\mathrm{OD})_{490 \mathrm{~nm}}$ values were measured. The viability of the non-treatment cells (control) was defined as 100\%, and the viability of cells from all other groups was calculated separately from that of the control group.

5-bromo-2'-deoxyuridine (BrdU) incorporation assay. DNA synthesis in proliferating cells was determined by measuring BrdU incorporation. BrdU assays were performed at 24 and $48 \mathrm{~h}$ following transfection of A549 and SK-MES-1 cells with miR-185 mimics or miR-185 inhibitor. Subsequent to seeding the infected cells in 96-well culture plates at a density of $2 \times 10^{3}$ cells/well, they were cultured for 24 or $48 \mathrm{~h}$, and incubated with a final concentration of $10 \mu \mathrm{M} B r d U$ (BD Pharmingen; BD Biosciences, San Jose, CA, USA) for between 2 and $24 \mathrm{~h}$. When the incubation period ended the medium was removed, and the cells were fixed for $30 \mathrm{~min}$ at room temperature and incubated with peroxidase-conjugated anti-BrdU-antibody (B8434, 1:1,000, Sigma-Aldrich; Merck $\mathrm{KGaA}$ ) for $60 \mathrm{~min}$ at room temperature. The cells were washed three times with PBS, incubated with peroxidase substrate (tetramethylbenzidine) for $30 \mathrm{~min}$, and the absorbance was measured at $450 \mathrm{~nm}$. Background BrdU immunofluorescence was determined in cells not exposed to BrdU and stained with the BrdU antibody.

In vitro invasion assays. Cells $\left(5 \times 10^{5}\right)$ were plated on the top side of polycarbonate Transwell filters coated with Matrigel (for Transwell matrix penetration assays) in the top chamber of the QCM 24-well cell invasion assay plates (Cell Biolabs, Inc., San Diego, CA, USA). Cells were suspended in medium without serum, and medium supplemented with $20 \%$ serum was used as a chemoattractant in the bottom chamber. The cells were incubated at $37^{\circ} \mathrm{C}$ for $48 \mathrm{~h}$. The noninvasive cells in the top chambers were removed with cotton swabs. The invasive cells on the lower membrane surface were fixed in $100 \%$ methanol for $10 \mathrm{~min}$ at $37^{\circ} \mathrm{C}$, air-dried, stained with DAPI (Beyotime Institute of Biotechnology, Haimen, China) for $5 \mathrm{~min}$ at $37^{\circ} \mathrm{C}$ and counted under an inverted microscope (IX81; Olympus Corporation, Tokyo, Japan) at a magnification of $x 100$. A total of three independent experiments were performed and the data are presented as the mean \pm standard deviation.

Cell scratch test. The cells were harvested, and the cell concentration was adjusted to $5 \times 10^{5} \mathrm{cell} / \mathrm{s} / \mathrm{ml}$. Cell suspensions $(100 \mu \mathrm{l})$ were plated in 96-well plates coated with Matrigel and routinely cultured until the cell monolayer emerged. The cell scratch test was subsequently performed. The cells were cultured in RPMI-1640 supplemented with $10 \mathrm{~g} / \mathrm{l}$ bovine serum albumin (Sigma-Aldrich; Merck KGaA) and $1 \%$ fetal bovine serum (FBS), and the scratch area was measured under an inverted microscope (IX81, Olympus Corporation) at a magnification of $x 100$. A total of $24 \mathrm{~h}$ subsequently, cell culture was continued for a further $24 \mathrm{~h}$ in RPMI-1640 supplemented with $10 \%$ FCS, and the relative distance of cell migration to the injury area was measured under the microscope.

Western blot analysis. The expression of SOX9, $\beta$-catenin and c-Myc in NSCLC cells was detected by immunoblotting. Cultured or transfected cells were lysed in radioimmunoprecipitation assay buffer (RIPA buffer, 89900, Thermo Fisher Scientific, Inc.) with $1 \%$ phenylmethylsulfonyl fluoride. Protein was extracted and protein concentration was determined according to bicinchoninic acid (BCA) protein quantification. Proteins $(20 \mu \mathrm{g} / \mathrm{lane})$ were loaded onto an $10 \%$ SDS-PAGE minigel and subsequently transferred onto a polyvinylidene fluoride membrane. Membranes were incubated in 5\% nonfat dry milk in PBS-0.1\% Tween for $1 \mathrm{~h}$ and then probed with the following antibodies at $4^{\circ} \mathrm{C}$ overnight: anti-SOX9 $(1: 1,000$; cat. no. EPR 14335-78; Abcam, Cambridge, UK), anti- $\beta$-catenin (1:5,000; cat. no. E247; Abcam), anti-c-Myc (1:10,000; cat. no. Y69; Abcam) and anti-GAPDH (1:500; cat. no. 6C5; Abcam). The blots were subsequently incubated with horseradish peroxidase-conjugated secondary antibody (1:5,000, cat. no. ab6728, Abcam). Enhanced chemiluminescence substrate was used to visualize the signals (EMD Millipore, Billerica, MA, USA). Data were analyzed by optical densitometry and ImageJ software (ImageJ bundled with 64-bit Java, version 1.6.0_24; National Institutes of Health, Bethesda, MD, USA). GAPDH was used as an endogenous protein for normalization.

RNA immunoprecipitation. RNA immunoprecipitation assays were performed using the Imprint RNA Immunoprecipitation kit (Sigma-Aldrich; Merck KGaA) with the protein argonaute-2 (AGO2) antibody (1:50; cat. no. 2897; Cell Signaling Technology, Inc., Danvers, MA, USA) or IgG antibody (1:50, A6066, Sigma-Aldrich; Merck KGaA). The AGO2 antibody was recovered using protein A/G beads. miR-185 and SOX9 RNA levels in the immunoprecipitates were measured by reverse transcription (RT)-qPCR analysis according to the protocol described above. 

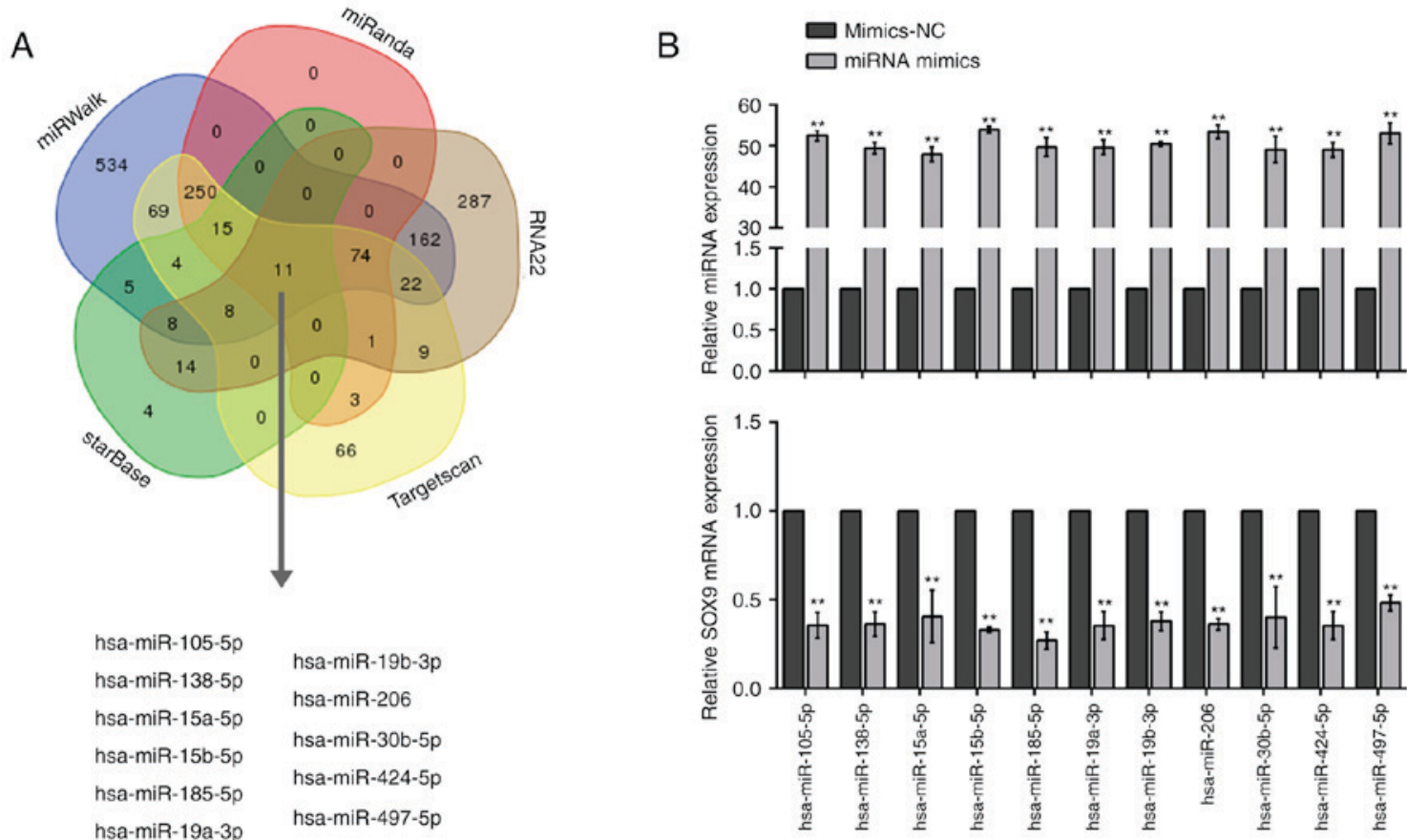

Figure 1. Screening and verification of candidate miRNAs of SOX9. (A) Online tools including miRWalk, miRanda, RNA22, Targetscan and starBase were employed to screen for the candidate miRNAs associated with SOX9. The following miRNAs were screened out: miR-105, miR-138, miR-15a, miR-15b, miR-19a, miR-19b, miR-206, miR-30b, miR-424, miR-497 and miR-185. Overexpression of the indicated miRNAs was achieved through transfection of miRNA mimics, compared with mimics-NC. (B) The miRNA mimics of the indicated miRNAs were transfected into A549 cells to achieve ectopic miRNA expression, as verified using qPCR assays. SOX9 mRNA expression in response to the ectopic miRNA expression of the indicated miRNAs was determined using qPCR assays. The mean value of the expression of controls was adjusted to 1 . The data are presented as mean \pm standard deviation of three independent experiments. ${ }^{* *} \mathrm{P}<0.01$ vs. respective mimics-NC group. NC, negative control; miRNA/miR, microRNA; SOX-9, SRY-box 9; qPCR, quantitative polymerase chain reaction.

Luciferase reporter assay. A total of $5 \times 10^{5}$ A549 cells were seeded into a 24-well plate. A wild-type and mutated SOX9 3'UTR (wt-SOX9 3'UTR, and mut-SOX9 3'UTR containing a 6-bp mutation in the predicted binding site of miR-185) luciferase reporter gene Renilla psiCHECK2 vector (Promega Corporation, Madison, WI, USA) was constructed. Following culturing overnight, cells were co-transfected with the indicated vectors, and miR-185 mimics and miR-185 inhibitor, respectively, by using Lipofectamine 2000 (Invitrogen; Thermo Fisher Scientific, Inc.). Luciferase assays were performed $48 \mathrm{~h}$ following transfection using the Dual Luciferase Reporter Assay System (Promega Corporation). Renilla luciferase activity was normalized to Firefly luciferase activity for each transfected well.

Statistical analysis. Data are presented as the mean \pm standard deviation of three independent experiments and processed using SPSS 17.0 statistical software (SPSS, Inc., Chicago, IL, USA). Using the Student's paired t-test, the expression of miR-185 in NSCLC tissues and paired adjacent normal tissues was compared. The differences between groups were evaluated using one-way analysis of variance followed by Turkey test. Kaplan-Meier analysis and the log-rank test were used to evaluate the effects of miR-185 expression on overall survival. $\mathrm{P}<0.05$ was considered to indicate a statistically significant difference.

\section{Results}

Screening and verification of candidate miRNAs of SOX9. Online tools including miRWalk, miRanda, RNA22,
starBase and Targetscan were used to screen out a number of candidate miRNAs which were associated with SOX9: miR-105, miR-138, miR-15a, miR-15b, miR-19a, miR-19b, miR-206, miR-30b, miR-424, miR-497 and miR-185 (Fig. 1A). The miRNA mimics of the indicated candidate miRNAs were transfected into A549 cells to achieve ectopic miRNA expressions, as verified by qPCR assays (Fig. 1B). SOX9 mRNA expression in response to ectopic miRNA expression was determined. The results demonstrated that SOX9 mRNA was downregulated by ectopic miRNA expression, and most markedly repressed by miR-185 (reduced by $73.1 \%$, meaning that SOX9 mRNA expression was reduced to $26.9 \%$ of that in the control group; Table I) (Fig. 1B), suggesting that miR-185 exerted the greatest inhibitory effect on SOX9 mRNA expression compared with the other candidate miRNAs. These data suggested that miR-185 may negatively regulate SOX9 mRNA expression in NSCLC cells; therefore, miR-185 was selected for use in further experiments.

Low miR-185 expression in NSCLC is associated with poorer clinicopathological parameters and shorter overall survival. In order to investigate the functions of miR-185 in NSCLC, the expression of miR-185 was monitored in NSCLC tissues. In 42 paired NSCLC tissues and the corresponding adjacent tissues, the expression of miR-185 was significantly decreased in NSCLC tissues compared with the corresponding normal tissues (Fig. 2A). In order to validate this result, RT-qPCR analysis was performed in 42 pairs of NSCLC tissues and adjacent normal tissues. Compared with the corresponding 
Table I. Inhibitory efficiency of miRNAs to SOX9.

miRNA mimics

\begin{tabular}{|c|c|c|c|c|c|c|}
\hline miRNA & Mimics-NC, normalized & Mean & Standard deviation & $\mathrm{N}$ & P-value & Inhibitory efficiency (\%) \\
\hline hsa-miR-105-5p & 1 & 0.355 & 0.060 & 3 & 0.108 & 64.5 \\
\hline hsa-miR-138-5p & 1 & 0.361 & 0.056 & 3 & 0.082 & 63.9 \\
\hline hsa-miR-15a-5p & 1 & 0.404 & 0.120 & 3 & 0.138 & 59.6 \\
\hline hsa-miR-15b-5p & 1 & 0.331 & 0.012 & 3 & 0.062 & 66.9 \\
\hline hsa-miR-185-5p & 1 & 0.269 & 0.040 & 3 & $\mathrm{~N} / \mathrm{A}$ & 73.1 \\
\hline hsa-miR-19a-3p & 1 & 0.354 & 0.063 & 3 & 0.120 & 64.6 \\
\hline hsa-miR-19b-3p & 1 & 0.378 & 0.042 & 3 & $0.031^{\mathrm{a}}$ & 62.2 \\
\hline hsa-miR-206 & 1 & 0.362 & 0.025 & 3 & $0.027^{\mathrm{a}}$ & 63.8 \\
\hline hsa-miR-30b-5p & 1 & 0.400 & 0.141 & 3 & 0.197 & 60.0 \\
\hline hsa-miR-424-5p & 1 & 0.354 & 0.064 & 3 & 0.123 & 64.6 \\
\hline hsa-miR-497-5p & 1 & 0.482 & 0.036 & 3 & $0.002^{\mathrm{b}}$ & 51.8 \\
\hline
\end{tabular}

${ }^{\mathrm{a}} \mathrm{P}<0.05,{ }^{\mathrm{b}} \mathrm{P}<0.01$ vs. mir-185-5p. SOX9, SRY-box 9; miRNA/miR, microRNA; NC, negative control.

normal tissues, miR-185 was demonstrated to be significantly downregulated [ $>2$-fold (i.e. $\log _{2}$ (fold change) $>1$ )] in 18 NSCLC cases (42.86\%; Fig. 2B). 42 pairs of NSCLC tissues were divided into two groups: A high miR-185 expression group (above the median miR-185 expression; $n=21$ ) and a low miR-185 expression group (below the median miR-185 expression; $n=21)$. Decreased expression of miR-185 in NSCLC was observed to be associated with increased tumor size $(\mathrm{P}=0.013)$ and more advanced tumor, node, metastasis (TNM) stage $(\mathrm{P}=0.030)$ as exhibited in Table II. In order to determine the potential association between miR-185 expression and patient prognosis, Kaplan-Meier analysis and the log-rank test were used to evaluate the effects of miR-185 expression on overall survival. The results indicated that patients with lower miR-185 expression had a significantly poorer prognosis compared with patients with higher miR-185 expression ( $\mathrm{P}=0.0288$; Fig. 1C). In addition, the expression of miR-185 was at a significantly lower level in the four human NSCLC cell lines, A549, H1299, H1650 and SK-MES-1, compared with the normal cell line, BEAS-2B (Fig. 1D). Among the four cell lines, miR-185 was expressed at lower levels in A549 and SK-MES-1 cell lines, which were thus chosen as further cell models. The above data suggested that miR-185 was expressed at a decreased level in NSCLC tissues and cell lines, and its low expression was associated with larger tumor size, advanced TNM stage and a shorter overall survival. Low miR-185 expression in NSCLC is associated with poorer prognosis; however, how miR-185 may affect NSCLC remains unclear.

Functions of miR-185 in the regulation of non-small cell lung cancer cell proliferation. Since the association between miR-185 and poorer prognosis in patients with NSCLC was demonstrated, a series of functional assays was performed to evaluate the functions of miR-185 in the regulation of NSCLC cell proliferation. A549 and SK-MES-1 cells were transfected with miR-185 mimics or miR-185 inhibitor to achieve ectopic miR-185 expression or miR-185 inhibition, as verified using qPCR assays (Fig. 3A). The cell viability and
Table II. Correlation between miR-185 expression and clinicopathological features in patients with non-small cell lung cancer.

\begin{tabular}{|c|c|c|c|c|}
\hline \multirow[b]{2}{*}{ Parameter } & \multirow[b]{2}{*}{ Group } & \multicolumn{2}{|c|}{$\begin{array}{c}\text { miR-185 } \\
\text { expression }\end{array}$} & \multirow[b]{2}{*}{ P-value } \\
\hline & & High & Low & \\
\hline \multirow[t]{2}{*}{ Age, years } & $<50$ & 12 & 13 & 0.753 \\
\hline & $\geq 50$ & 9 & 8 & \\
\hline \multirow[t]{2}{*}{ Sex } & Female & 6 & 7 & 0.739 \\
\hline & Male & 15 & 14 & \\
\hline \multirow[t]{2}{*}{ Tumor size, $\mathrm{cm}$} & $<3$ & 14 & 6 & $0.013^{\mathrm{a}}$ \\
\hline & $\geq 3$ & 7 & 15 & \\
\hline \multirow[t]{2}{*}{ Histology } & Adenoma & 11 & 14 & 0.346 \\
\hline & Squamous & 10 & 7 & \\
\hline \multirow[t]{2}{*}{ Differentiation } & Moderate-poor & 8 & 13 & 0.123 \\
\hline & Well & 13 & 8 & \\
\hline \multirow[t]{2}{*}{ TNM stage } & $\mathrm{I}+\mathrm{II}$ & 13 & 6 & $0.030^{\mathrm{a}}$ \\
\hline & III + IV & 8 & 15 & \\
\hline \multicolumn{5}{|c|}{ Lymph node metastasis } \\
\hline & Absence & 11 & 7 & 0.212 \\
\hline & Presence & 10 & 14 & \\
\hline
\end{tabular}

${ }^{\mathrm{a}} \mathrm{P}<0.05$ vs. low miR-185 expression. TNM, tumor, node metastasis; miR, microRNA.

DNA synthesis capability of miR-185 mimics- or miR-185 inhibitor-transfected A549 and SK-MES-1 cells were determined using MTT and BrdU assays. The results demonstrated that the cell viability and DNA synthesis capability of NSCLC cells were significantly downregulated by ectopic miR-185 expression, and promoted by miR-185 inhibition (Fig. 3B-E). 

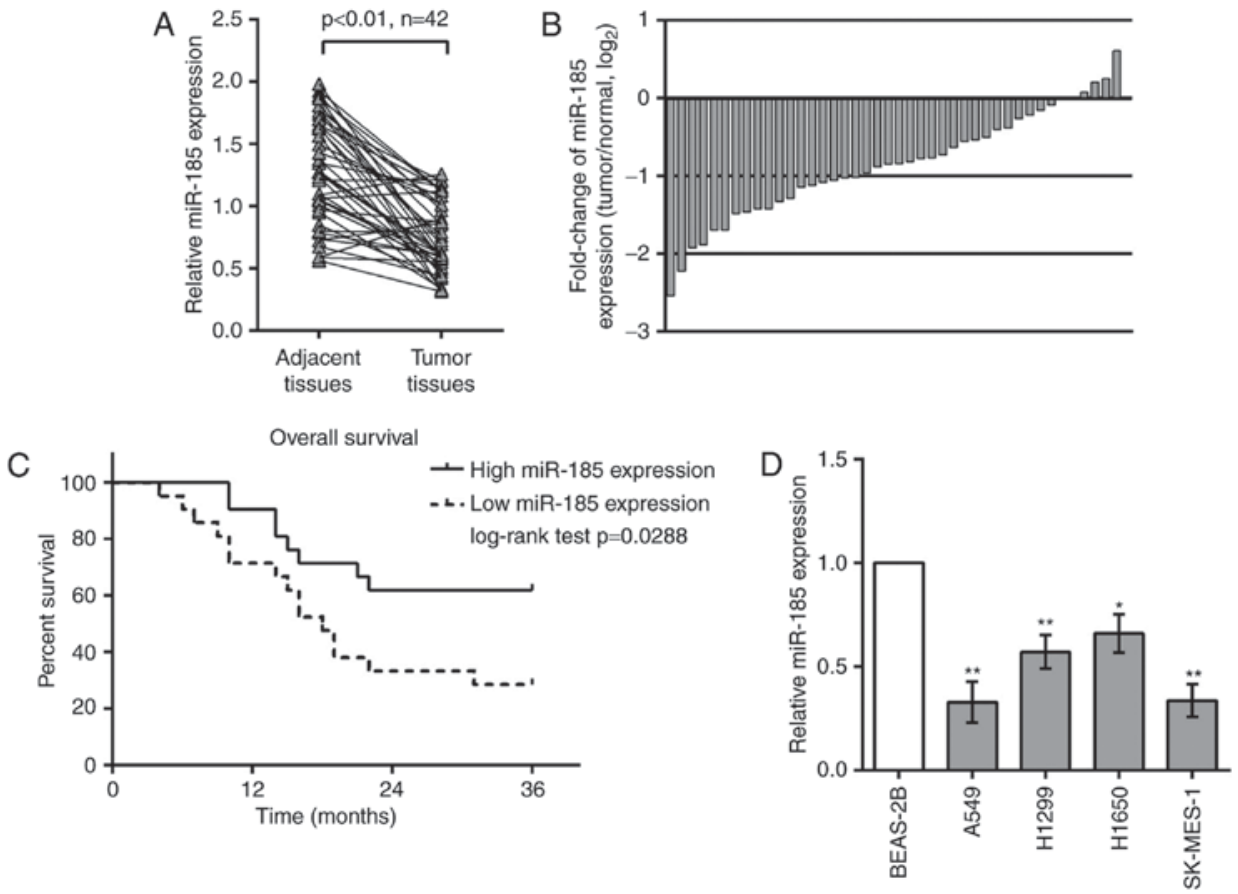

Figure 2. Low miR-185 expression in NSCLC is associated with poorer clinicopathological parameters and shorter overall survival. (A) miR-185 expression in 42 pairs of NSCLC tissues was determined using qPCR assays, compared with the adjacent tissues. (B) The expression of miR-185 in 42 pairs of NSCLC tissues and their corresponding adjacent non-tumorous tissues was analyzed. The expression level of miR-185 was determined by qPCR and normalized to U6. Fold changes were analyzed using the $2^{-\Delta \Delta C q}$ method. (C) Kaplan-Meier overall survival curves for 42 patients with NSCLC classified according to relative miR-185 expression level. (D) miR-185 expression in NSCLC cell lines A549, H1299, H1650 and SK-MES-1, and normal cell line BEAS-2B using qPCR assays. The data are presented as the mean \pm standard deviation of three independent experiments. ${ }^{*} \mathrm{P}<0.05,{ }^{* *} \mathrm{P}<0.01$ vs. BEAS-2B. miR, microRNA; qPCR, quantitative polymerase chain reaction; NSCLC, non-small cell lung cancer.
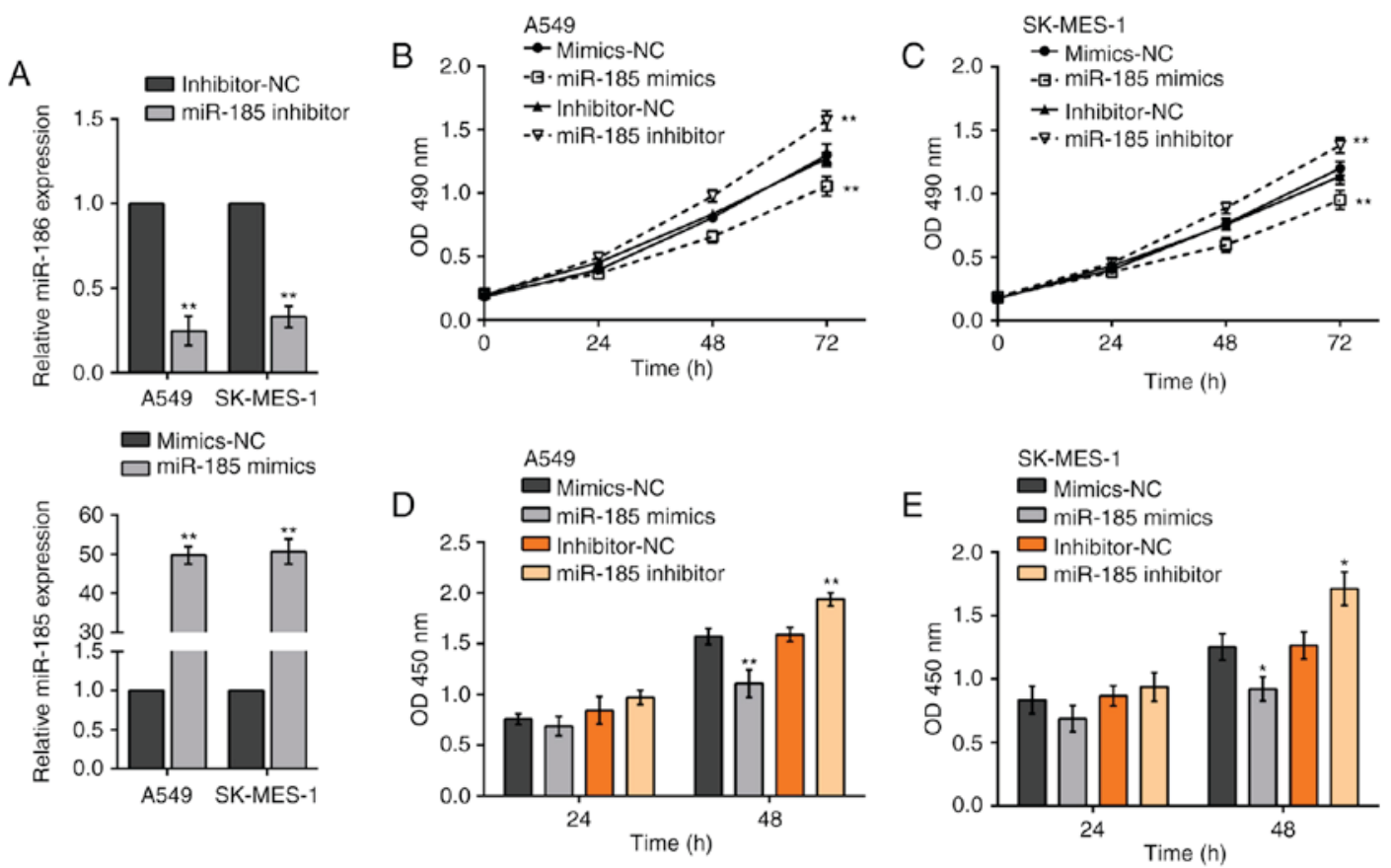

Figure 3. Functions of miR-185 in the regulation of non-small cell lung cancer cell proliferation. (A) A549 and SK-MES-1 cells were transfected with miR-185 mimics or miR-185 inhibitor to achieve ectopic miR-185 expression or miR-185 inhibition, as verified using quantitative polymerase chain reaction assays. The cell viability of (B) A549 and (C) SK-MES-1 cells was determined using MTT assays. The DNA synthesis capability of (D) A549 and (E) SK-MES-1 cells was determined using 5-bromo-2'-deoxyuridine assays. The data are presented as the mean \pm standard deviation of three independent experiments. " $\mathrm{P}<0.05$, ${ }^{* *} \mathrm{P}<0.01$ vs. respective mimics-NC group. $\mathrm{NC}$, negative control; miR, microRNA; OD, optical density.

These data indicated that miR-185 was able to negatively regulate the cell proliferation of NSCLC cells.
Effects of miR-185 on NSCLC cell invasion and migration. The results of the present study demonstrated that miR-185 
A

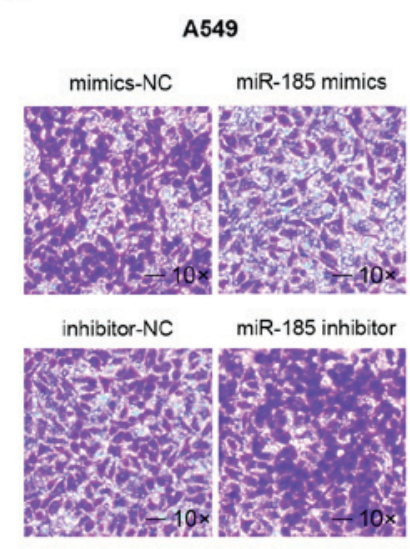

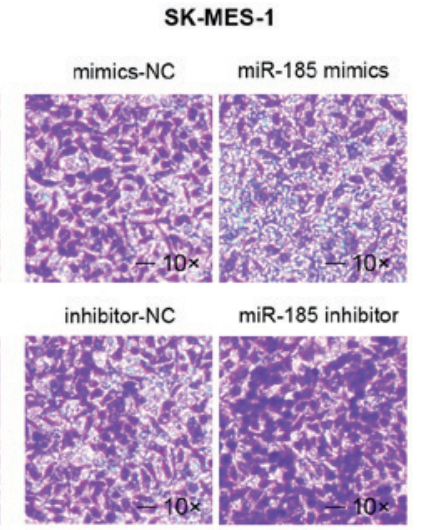

B

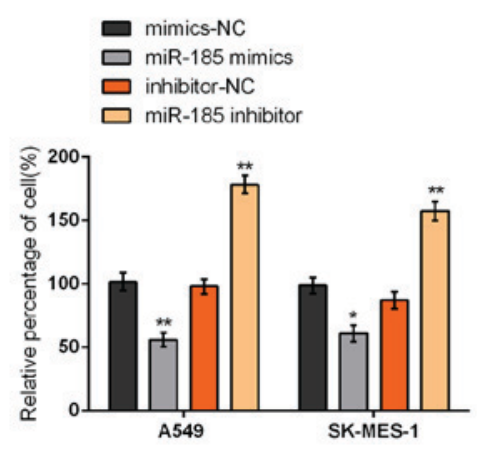

C

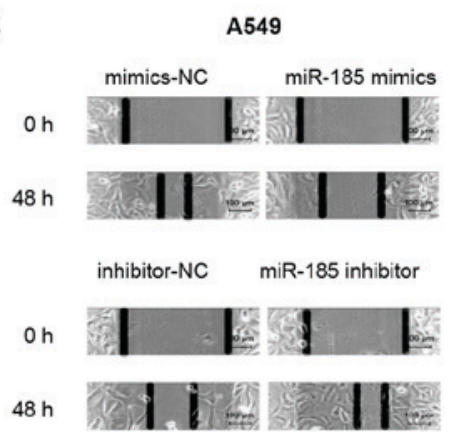

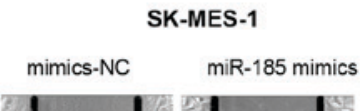
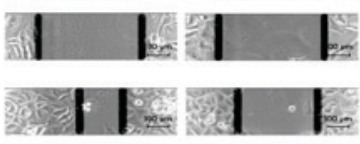

inhibitor-NC miR-185 inhibitor

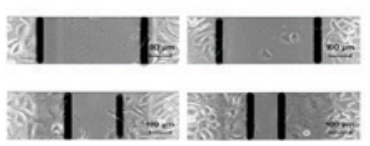

D

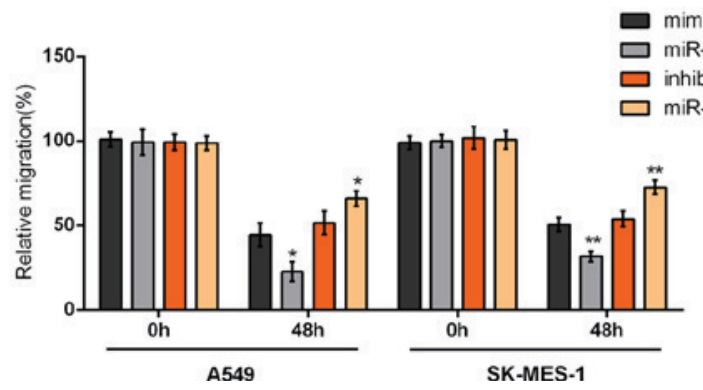

Figure 4. Effects of miR-185 on non-small cell lung cancer cell invasion and migration. A549 and SK-MES-1 cells were transfected with miR-185 mimics or miR-185 inhibitor to achieve ectopic miR-185 expression or miR-185 inhibition. The cell invasion capability of A549 and SK-MES-1 cells was determined using Transwell assays. (A) Representative images and (B) statistical analysis are presented. The cell migration capability of A549 and SK-MES-1 cells was determined using a cell scratch test. (C) Representative images and (D) statistical analysis are presented. The data are presented as the mean \pm standard deviation of three independent experiments. ${ }^{*} \mathrm{P}<0.05,{ }^{* *} \mathrm{P}<0.01$ vs. respective mimics-NC group. NC, negative control; miR, microRNA.

was able to negatively regulate NSCLC cell proliferation; in addition, the effects of miR-185 on NSCLC cell invasion and migration were investigated. Using a Transwell assay and a cell scratch test, the cell invasion and migration capabilities of miR-185 mimics- or miR-185 inhibitor-transfected NSCLC cells were determined. The results demonstrated that ectopic miR-185 significantly suppressed the cell invasion and migration capability of A549 and SK-MES-1 cells, whereas miR-185 inhibition promoted the indicated capability (Fig. 4). These data suggested that, in addition to cell proliferation, miR-185 may be involved in inhibiting NSCLC cell invasion and migration.

miR-185 inversely regulates SOX9 expression through direct binding to the 3'UTR of SOX9. As mentioned above, SOX9 has been reported to act as an oncogene in NSCLC, and may be regulated by a number of miRNAs. The present study further investigated whether miR-185 may regulate NSCLC cell proliferation, invasion and migration via regulation of SOX9. A wild-type and mutated SOX9 3'UTR (wt-SOX9 3'UTR and mut-SOX9 3'UTR, containing a 6-bp mutation in the predicted binding site of miR-185) luciferase reporter gene vector was constructed (Fig. 5A). A549 cells were co-transfected with the indicated vectors, and miR-185 mimics and miR-185 inhibitor, respectively. The luciferase activity was determined using dual luciferase assays. The results demonstrated that the luciferase activity of the wild-type vectors was significantly suppressed by miR-185 mimics and amplified by miR-185 inhibitor; following mutation in the predicted binding site of miR-185, the luciferase activity alterations were abolished (Fig. 5B).

To further confirm the interaction between miR-185 and the SOX9 3'UTR, RNA immunoprecipitation assays were performed. AGO2 promotes target mRNA degradation or inhibits its protein translation; it has been regarded as the 

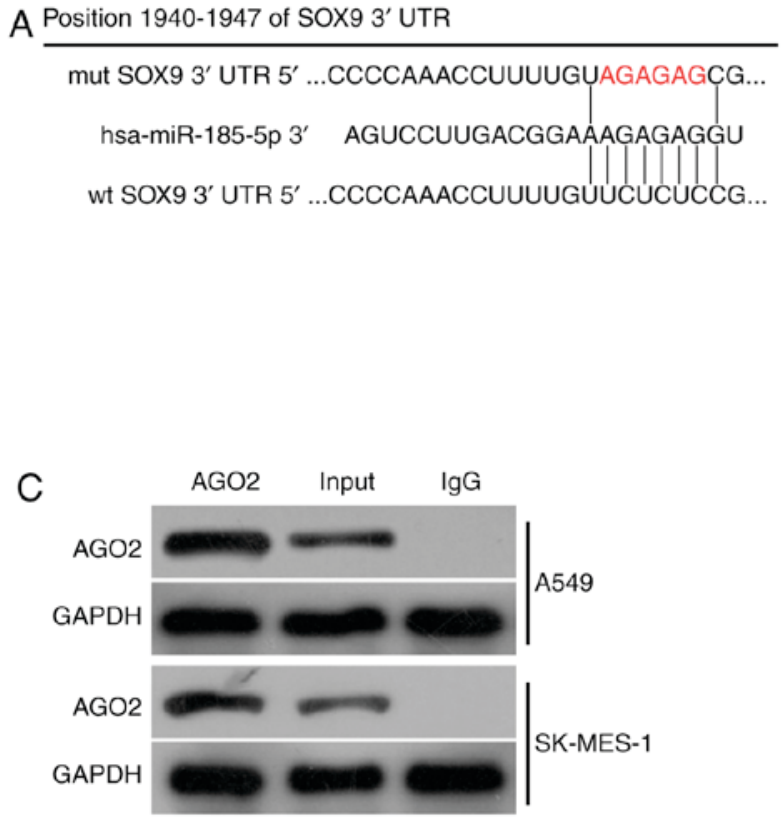
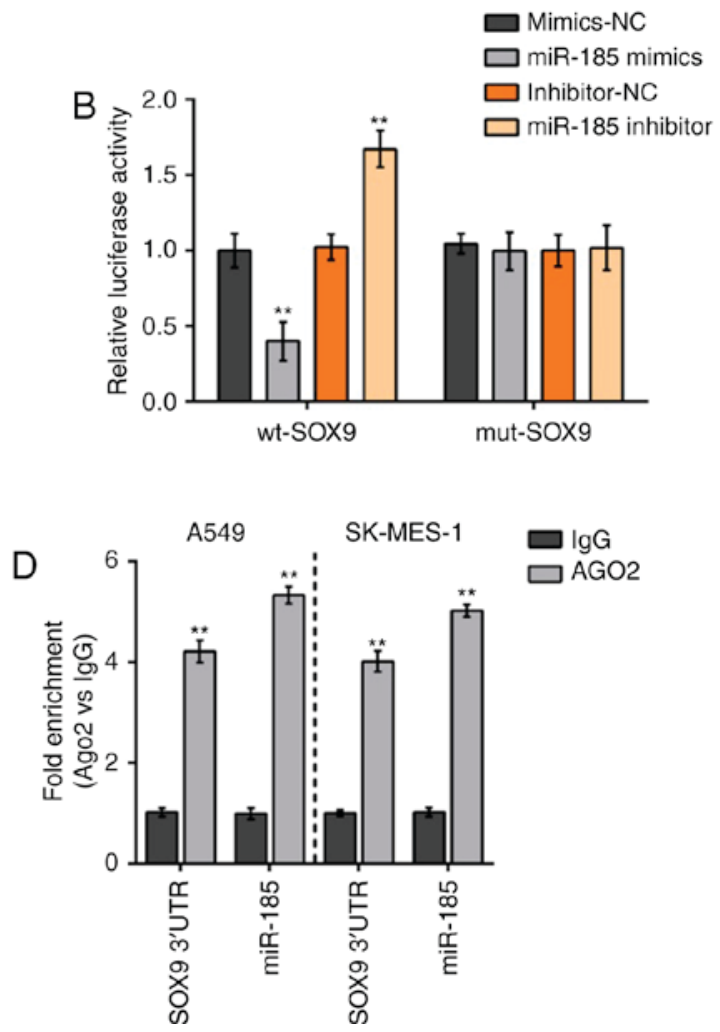

Figure 5. miR-185 inversely regulates SOX9 expression through direct binding to the 3'UTR of SOX9. (A) Wt-SOX9 3'UTR and mut-SOX9 3'UTR, containing a 6-bp mutation in the predicted binding site of miR-185, luciferase reporter gene vectors were constructed. A549 cells were co-transfected with the indicated vectors and miR-185 mimics and miR-185 inhibitor, respectively. (B) Luciferase assays were performed to determine the luciferase activity $48 \mathrm{~h}$ following transfection using a dual luciferase reporter assay system. ${ }^{* *} \mathrm{P}<0.01$ vs. mimics-NC. The association between miR-185/SOX9 and AGO2 was determined. A549 cellular lysates were used for RNA immunoprecipitation with an AGO2 antibody. Detection of AGO2 and IgG using (C) western blotting, and detection of miR-185 or SOX9 using (D) reverse transcription-quantitative polymerase chain reaction analysis. All data of SOX9 expression were normalized to GAPDH mRNA expression levels. miR-185 expression data was normalized to U6 small RNA expression. The data are presented as the mean \pm standard deviation of three independent experiments. ${ }^{* *} \mathrm{P}<0.01$ vs. respective IgG group. NC, negative control; SOX9, SRY-box 9; UTR, untranslated region; mut, mutated; wt, wild type; miR, microRNA; IgG, immunoglobulin G; AGO2, protein argonaute-2.

core component of the RNA-induced silencing complex (RISC) (22). RNA immunoprecipitation was performed in the present study with the AGO2 antibody, to investigate whether miR-185 may regulate SOX9 expression via the RNA interference (RNAi) pathway. As exhibited by western blot analysis, AGO2 protein was precipitated from the cellular extract of A549 and SK-MES-1 cells (Fig. 5C). In the RNA extracted from the precipitated AGO2 protein, it was possible to detect the miR-185 and SOX9 3'UTR with a 4-fold enrichment compared with IgG (Fig. 5D), indicating that miR-185 and the SOX9 3'UTR existed in RISC. These data indicated that miR-185 may regulate SOX9 expression via the RNAi pathway.

Downstream Wht signaling of SOX9 is involved in the miR-185 regulation of NSCLC cell proliferation, invasion and migration. SOX9 has been reported to activate Wnt signaling, which is essential for the maintenance of cell proliferation (23), to exert its oncogenic function in a number of types of cancer $(23,24)$. The present study investigated whether Wnt signaling was involved in the miR-185/SOX9 regulation of NSCLC cell proliferation, invasion and migration. A549 and SK-MES-1 cells were transfected with miR-185 mimics or miR-185 inhibitor; the protein levels of SOX9, $\beta$-catenin and c-Myc were determined using western blot analysis. The results demonstrated that the protein levels of SOX $9, \beta$-catenin and c-Myc were significantly reduced by ectopic miR-185 expression, and increased by miR-185 inhibition (Fig. 6A and B), indicating that miR-185 may inhibit SOX9 expression to suppress NSCLC cell proliferation, invasion and migration.

The mRNA expression of SOX9, $\beta$-catenin and c-Myc was additionally evaluated in NSCLC tissues and normal tissues. The results demonstrated that, in NSCLC tissues, SOX9, $\beta$-catenin and c-Myc mRNA was significantly upregulated compared with normal tissues (Fig. 6C-E). Additionally, an inverse correlation was observed between miR-185, and SOX9, $\beta$-catenin and c-Myc, respectively, by performing Spearman's rank correlation analysis (Fig. 6F-H). These data further indicated that rescuing miR-185 expression, thus inhibiting SOX9 and its downstream Wnt signaling, may be a promising strategy for the treatment of NSCLC.

\section{Discussion}

The present study identified miR-185 to be a novel candidate miRNA which was able to inversely regulate SOX9 expression in NSCLC. miR-185 was markedly downregulated in NSCLC cancer tissues and cell lines, compared with corresponding non-cancer tissues and a normal cell line. Patients with NSCLC exhibiting low miR-185 expression had a significantly poorer prognosis, compared with those with high expression. Ectopic 
A

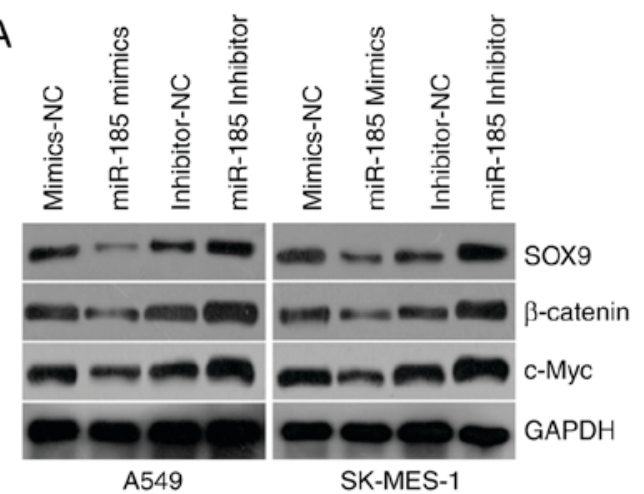

B

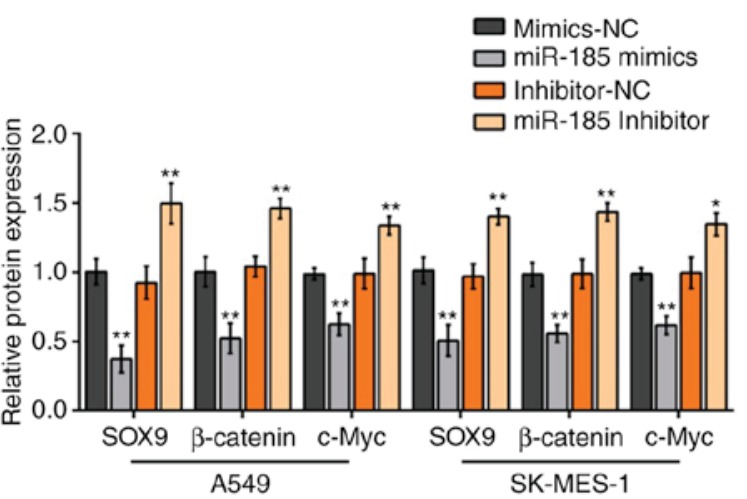

C

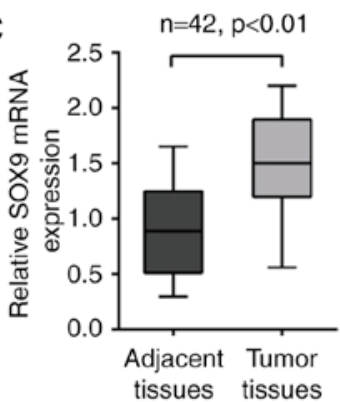

D
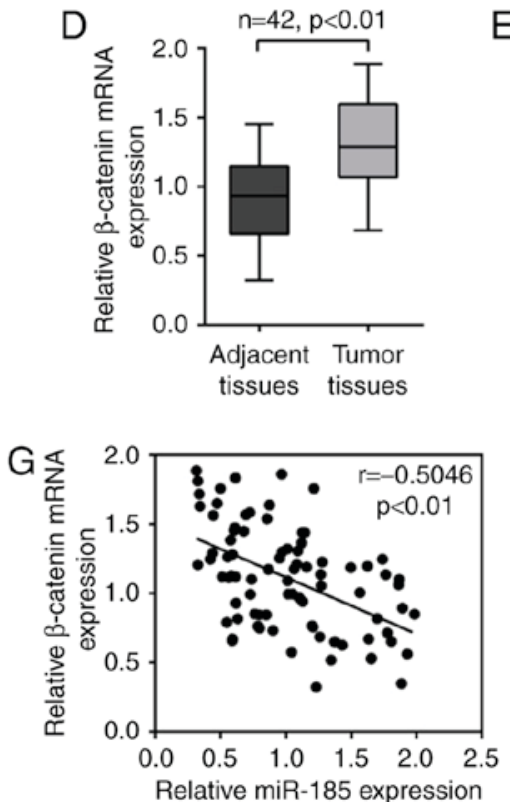

Relative miR-185 expression
E

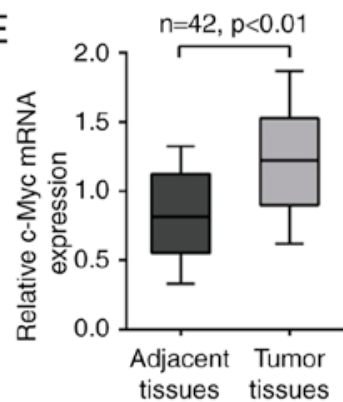

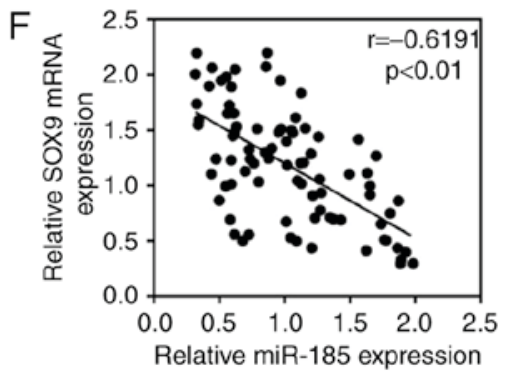

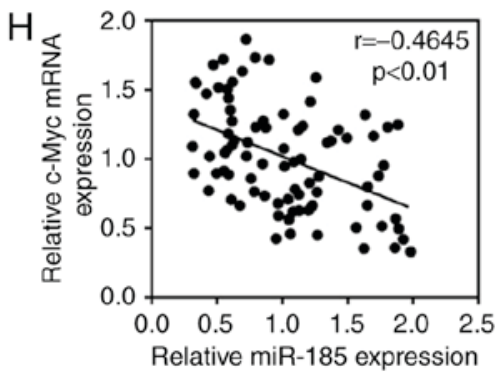

Figure 6. Downstream Wnt signaling of SOX9 is involved in the miR-185 regulation of NSCLC cell proliferation, invasion and migration. A549 and SK-MES-1 cells were transfected with miR-185 mimics or miR-185 inhibitor; the protein levels of SOX9, $\beta$-catenin and c-Myc in A549 and SK-MES-1 cells were determined using (A) western blotting and (B) densitometric analysis. The data are presented as the mean \pm standard deviation of three independent experiments ${ }^{*} \mathrm{P}<0.05,{ }^{* *} \mathrm{P}<0.01$ vs. respective mimics-NC group. The mRNA expression of (C) SOX9, (D) $\beta$-catenin and (E) c-Myc in NSCLC tissues and adjacent normal tissues was determined using quantitative polymerase chain reaction analysis. The correlation between miR-185 and (F) SOX9, $(\mathrm{G}) \beta$-catenin and (H) c-Myc, respectively, was analyzed by Spearman's rank correlation analysis. SOX9, SRY-box 9; miR, microRNA; c-Myc, c-Myc proto-oncogene protein; NC, negative control; NSCLC, non-small cell lung cancer.

miR-185 expression in NSCLC cells significantly suppressed cell proliferation, invasion and migration. In addition, via direct binding to the 3'UTR of SOX9, miR-185 inversely regulated the downstream Wnt signaling-associated factors, $\beta$-catenin and c-Myc. SOX9, $\beta$-catenin and c-Myc mRNA expression was upregulated in NSCLC tissues, and inversely correlated with miR-185 expression, further indicating that rescuing miR-185 expression, thereby inhibiting SOX9 and downstream Wnt signaling, may be a promising strategy for the treatment of NSCLC.

It was previously reported that human NSCLC is associated with upregulation of SOX9 expression. As a well-studied oncogenic factor, SOX9 mRNA and protein is upregulated in all stages of human NSCLC, and this upregulation has been reported to promote NSCLC progression by promoting cell proliferation, invasion and migration $(18,25,26)$. According to previous studies, a large number of miRNAs have been identified to function as either tumor suppressor genes or oncogenes in NSCLC, through regulation of target genes (15). Identifying novel miRNAs and the corresponding targets is essential for the diagnosis, prevention and treatment of NSCLC, which may provide a promising therapeutic opportunity for this disease. In the present study, a series of online tools was used to elucidate novel candidate miRNAs which may regulate SOX9 expression in NSCLC tissues and cell lines. As exhibited by Venn diagram, a total of eleven candidate miRNAs were predicted to possess possible binding sites for SOX9. As mentioned above, miR-592 and miR-124 have been reported to be associated with lung cancer in previous studies $(18,27,28)$; however, these miRNAs did not appear in the prediction results in the present study. The reason for this may be the different strategies used by different online tools, and the candidate miRNAs in the present study were selected based on the results of cross-matching of the selected online tools. Among the 11 screened-out candidate miRNAs, miR-185 suppressed SOX9 expression the most strongly. Previously, miR-185 has been reported to act as a tumor suppressor in gastric cancer $(29,30)$, breast cancer (31) and NSCLC $(32,33)$. In order to further investigate the 
functional roles and mechanism of miR-185 in NSCLC, a series of functional assays was employed.

miR-185 expression has been reported to be downregulated in breast cancer tissues and cell lines (31). Low expression levels of miR-185 were associated with lymph node metastasis, clinical stage, overall survival and relapse-free survival in triple-negative breast cancer (34). Consistent with these studies, decreased miR-185 expression in NSCLC tissues was observed in the present study. The potential association between miR-185 expression and clinicopathological features in patients with NSCLC was additionally evaluated. Decreased expression of miR-185 was correlated with larger tumor size, advanced TNM stage and shorter overall survival of patients with NSCLC. In order to investigate how miR-185 may affect NSCLC progression, the roles of miR-185 in regulation of NSCLC cell proliferation, invasion and migration were additionally investigated. Through transfection with miR-185 mimics or miR-185 inhibitor into A549 and SK-MES-1 cells, ectopic miR-185 expression or miR-185 inhibition was achieved. The cell proliferation, invasion and migration capabilities of NSCLC cells were subsequently evaluated. Ectopic miR-185 expression significantly suppressed NSCLC cell proliferation, invasion and migration; by contrast, miR-185 inhibition promoted NSCLC cell proliferation, invasion and migration. Notably, among the clinicopathological features analyzed, low miR-185 expression was not correlated with lymph node metastasis. It was hypothesized that miR-185 may affect the migration capability of NSCLC cells, although it may not be an independent risk factor of lymph node metastasis, which requires further investigation in future studies.

miRNAs have been identified to function as either tumor suppressor genes or oncogenes in NSCLC by regulating the expression of target genes (15). miR-185 serves as a tumor suppressor by inducing cell cycle arrest in NSCLC cell lines (32); additionally, miR-185 reportedly targets RAC- $\alpha$ serine/threonine protein kinase (33) or multidrug resistance-associated protein 1 to suppress NSCLC or modulate the chemosensitivity of human NSCLC to cisplatin (35). Notably, a number of miRNAs, including miR-124 (19), miR-206 (26) and miR-32 (25), are involved in the regulation of SOX9 activity in lung cancer. Given the essential role of SOX9 in NSCLC, and that miR-185 possesses a potential binding site for SOX9, luciferase reporter gene and RNA immunoprecipitation assays were used to confirm that hypothesis that SOX9 was a direct target of miR-185. The results of the present study indicated that miR-185 may suppress NSCLC cell proliferation, invasion and migration by directly targeting SOX9. Previously, SOX9 has been reported to activate Wnt signaling to promote cancer progression (24,36-38). The present study additionally investigated whether Wnt signaling may be involved in the chemoresistance of lung cancer cells. As verified by western blot analysis, the protein levels of SOX $9, \beta$-catenin and c-Myc were significantly reduced by ectopic miR-185 expression and promoted by miR-185 inhibition, indicating the involvement of Wnt signaling in the miR-185-mediated regulation of NSCLC cell proliferation, invasion and migration.

In conclusion, it was observed in the present study that the mRNA expression levels of SOX9, $\beta$-catenin and c-Myc in
NSCLC tissues were significantly downregulated compared with normal tissues. In addition, miR-185 expression was inversely correlated with SOX9, $\beta$-catenin and c-Myc, respectively, in NSCLC tissues, indicating that rescuing miR-185 expression in NSCLC, thereby inhibiting SOX9 expression and downstream Wnt signaling, leading to suppression of NSCLC cell proliferation, invasion and migration, may be a promising strategy for the treatment of NSCLC.

\section{Acknowledgements}

The present study was supported by the Special Fund of Clinical Medical Science and Technology of Jiangsu Province (grant no. BL213023).

\section{References}

1. Siegel R, Ma J, Zou Z and Jemal A: Cancer statistics 2014. CA Cancer J Clin 64: 9-29, 2014.

2. Zappa C and Mousa SA: Non-small cell lung cancer: Current treatment and future advances. Transl Lung Cancer Res 5: 288-300, 2016.

3. Sher T, Dy GK and Adjei AA: Small cell lung cancer. Mayo Clin Proc 83: 355-367, 2008.

4. Shtivelman E, Hensing T, Simon GR, Dennis PA, Otterson GA, Bueno R and Salgia R: Molecular pathways and therapeutic targets in lung cancer. Oncotarget 5: 1392-1433, 2014.

5. Schnabel PA and Junker K: Neuroendocrine tumors of the lungs. From small cell lung carcinoma to diffuse idiopathic pulmonary neuroendocrine cell hyperplasia. Pathologe 35: 557-564, 2014 (In German).

6. Harley VR, Clarkson MJ and Argentaro A: The molecular action and regulation of the testis-determining factors, SRY (sex-determining region on the Y chromosome) and SOX9 SRY-related high-mobility group (HMG) box 9. Endocr Rev 24: 466-487, 2003.

7. Wagner T, Wirth J, Meyer J, Zabel B, Held M,Zimmer J, Pasantes J, Bricarelli FD, Keutel J, Hustert E, et al: Autosomal sex reversal and campomelic dysplasia are caused by mutations in and around the SRY-related gene SOX9. Cell 79: 1111-1120, 1994.

8. Foster JW, Dominguez-Steglich MA, Guioli S, Kwok C, Weller PA, Stevanović M, Weissenbach J, Mansour S, Young ID, Goodfellow PN, et al: Campomelic dysplasia and autosomal sex reversal caused by mutations in an SRY-related gene. Nature 372: 525-530, 1994

9. Zhou CH, Ye LP, Ye SX, Li Y, Zhang XY, Xu XY and Gong LY: Clinical significance of SOX9 in human non-small cell lung cancer progression and overall patient survival. J Exp Clin Cancer Res 31: 18, 2012.

10. Guo H, Ingolia NT, Weissman JS and Bartel DP: Mammalian microRNAs predominantly act to decrease target mRNA levels. Nature 466: 835-840, 2010.

11. Fabian MR, Sonenberg N and Filipowicz W: Regulation of mRNA translation and stability by microRNAs. Annu Rev Biochem 79: 351-379, 2010.

12. McManus MT: MicroRNAs and cancer. Semin Cancer Biol 13: 253-258, 2003.

13. Bartel DP: MicroRNAs: Genomics, biogenesis, mechanism, and function. Cell 116: 281-297, 2004.

14. Farazi TA, Spitzer JI, Morozov P and Tuschl T: miRNAs in human cancer. J Pathol 223: 102-115, 2011.

15. Skrzypski M, Dziadziuszko R and Jassem J: MicroRNA in lung cancer diagnostics and treatment. Mutat Res 717: 25-31, 2011

16. Boeri M, Sestini S, Fortunato O, Verri C, Suatoni P, Pastorino U and Sozzi G: Recent advances of microRNA-based molecular diagnostics to reduce false-positive lung cancer imaging. Expert Rev Mol Diagn 15: 801-813, 2015.

17. Guan P, Yin Z, Li X, Wu W and Zhou B: Meta-analysis of human lung cancer microRNA expression profiling studies comparing cancer tissues with normal tissues. J Exp Clin Cancer Res 31: $54,2012$.

18. Li Z, Li B, Niu L and Ge L: miR-592 functions as a tumor suppressor in human non-small cell lung cancer by targeting SOX9. Oncol Rep 37: 297-304, 2017. 
19. Wang X, Liu Y, Liu X, Yang J, Teng G, Zhang L and Zhou C: MiR-124 inhibits cell proliferation, migration and invasion by directly targeting SOX9 in lung adenocarcinoma. Oncol Rep 35: 3115-3121, 2016.

20. Miranda KC, Huynh T, Tay Y, Ang YS, Tam WL, Thomson AM, Lim B and Rigoutsos I: A pattern-based method for the identification of MicroRNA binding sites and their corresponding heteroduplexes. Cell 126: 1203-1217, 2006.

21. Livak KJ and Schmittgen TD: Analysis of relative gene expression data using real-time quantitative PCR and the 2(-Delta Delta C(T)) method. Methods 25: 402-408, 2001.

22. Ikeda K, Satoh M, Pauley KM, Fritzler MJ, Reeves WH and Chan EK: Detection of the argonaute protein Ago2 and microRNAs in the RNA induced silencing complex (RISC) using a monoclonal antibody. J Immunol Methods 317: 38-44, 2006.

23. Belo J, Krishnamurthy M, Oakie A and Wang R: The role of SOX 9 transcription factor in pancreatic and duodenal development. Stem Cells Dev 22: 2935-2943, 2013.

24. Ma F, Ye H, He HH, Gerrin SJ, Chen S, Tanenbaum BA, Cai C, Sowalsky AG, He L, Wang H, et al: SOX9 drives WNT pathway activation in prostate cancer. J Clin Invest 126: 1745-1758, 2016.

25. Zhu D, Chen H, Yang X, Chen W, Wang L, Xu J and Yu L: miR-32 functions as a tumor suppressor and directly targets SOX9 in human non-small cell lung cancer. Onco Targets Ther 8: 1773-1783, 2015.

26. Zhang YJ, Xu F, Li HB, Han JC and Li L: miR-206 inhibits non small cell lung cancer cell proliferation and invasion by targeting SOX9. Int J Clin Exp Med 8: 9107-9113, 2015.

27. Xie C, Han Y,Liu Y,Han L and Liu J: miRNA-124 down-regulates SOX8 expression and suppresses cell proliferation in non-small cell lung cancer. Int J Clin Exp Pathol 7: 6534-6542, 2014.

28. Zu L, Xue Y, Wang J, Fu Y, Wang X, Xiao G, Hao M, Sun X, Wang Y, Fu G and Wang J: The feedback loop between miR-124 and TGF- $\beta$ pathway plays a significant role in non-small cell lung cancer metastasis. Carcinogenesis 37: 333-343, 2016.

29. Qiu F, Xiong JP, Deng J and Xiang XJ: TRIM29 functions as an oncogene in gastric cancer and is regulated by miR-185. Int J Clin Exp Pathol 8: 5053-5061, 2015.

30. Tan Z, Jiang H, Wu Y, Xie L, Dai W, Tang H and Tang S: miR-185 is an independent prognosis factor and suppresses tumor metastasis in gastric cancer. Mol Cell Biochem 386: 223-231, 2014
31. Zou Q, Wu H, Fu F, Yi W, Pei L and Zhou M: RKIP suppresses the proliferation and metastasis of breast cancer cell lines through up-regulation of miR-185 targeting HMGA2. Arch Biochem Biophys 610: 25-32, 2016

32. Takahashi Y, Forrest AR, Maeno E, Hashimoto T, Daub CO and Yasuda J: MiR-107 and MiR-185 can induce cell cycle arrest in human non small cell lung cancer cell lines. PLoS One 4: e6677, 2009.

33. Li S, Ma Y, Hou X, Liu Y, Li K, Xu S and Wang J: MiR-185 acts as a tumor suppressor by targeting AKT1 in non-small cell lung cancer cells. Int J Clin Exp Pathol 8: 11854-11862, 2015.

34. Tang H, Liu P, Yang L, Xie X, Ye F, Wu M, Liu X, Chen B, Zhang $\mathrm{L}$ and $\mathrm{Xie} \mathrm{X}$ : miR-185 suppresses tumor proliferation by directly targeting E2F6 and DNMT1 and indirectly upregulating BRCA1 in triple-negative breast cancer. Mol Cancer Ther 13: 3185-3197, 2014.

35. Pei K, Zhu JJ, Wang CE, Xie QL and Guo JY: MicroRNA-185-5p modulates chemosensitivity of human non-small cell lung cancer to cisplatin via targeting ABCC1. Eur Rev Med Pharmacol Sci 20: 4697-4704, 2016.

36. Santos JC, Carrasco-Garcia E, Garcia-Puga M, Aldaz P, Montes M, Fernandez-Reyes M, de Oliveira CC, Lawrie CH, Araúzo-Bravo MJ, Ribeiro ML and Matheu A: SOX9 elevation acts with canonical WNT signaling to drive gastric cancer progression. Cancer Res 76: 6735-6746, 2016.

37. Liu H, Liu Z, Jiang B, Peng R, Ma Z and Lu J: SSOX9 overexpression promotes Glioma metastasis via Wnt/ $\beta$-catenin signaling. Cell Biochem Biophys 73: 205-212, 2015.

38. Wu KF, Liang WC, Feng L, Pang JX, Waye MM, Zhang JF and Fu WM: H19 mediates methotrexate resistance in colorectal cancer through activating Wnt/ $\beta$-catenin pathway. Exp Cell Res 350: 312-317, 2017.

This work is licensed under a Creative Commons Attribution-NonCommercial-NoDerivatives 4.0 International (CC BY-NC-ND 4.0) License. 